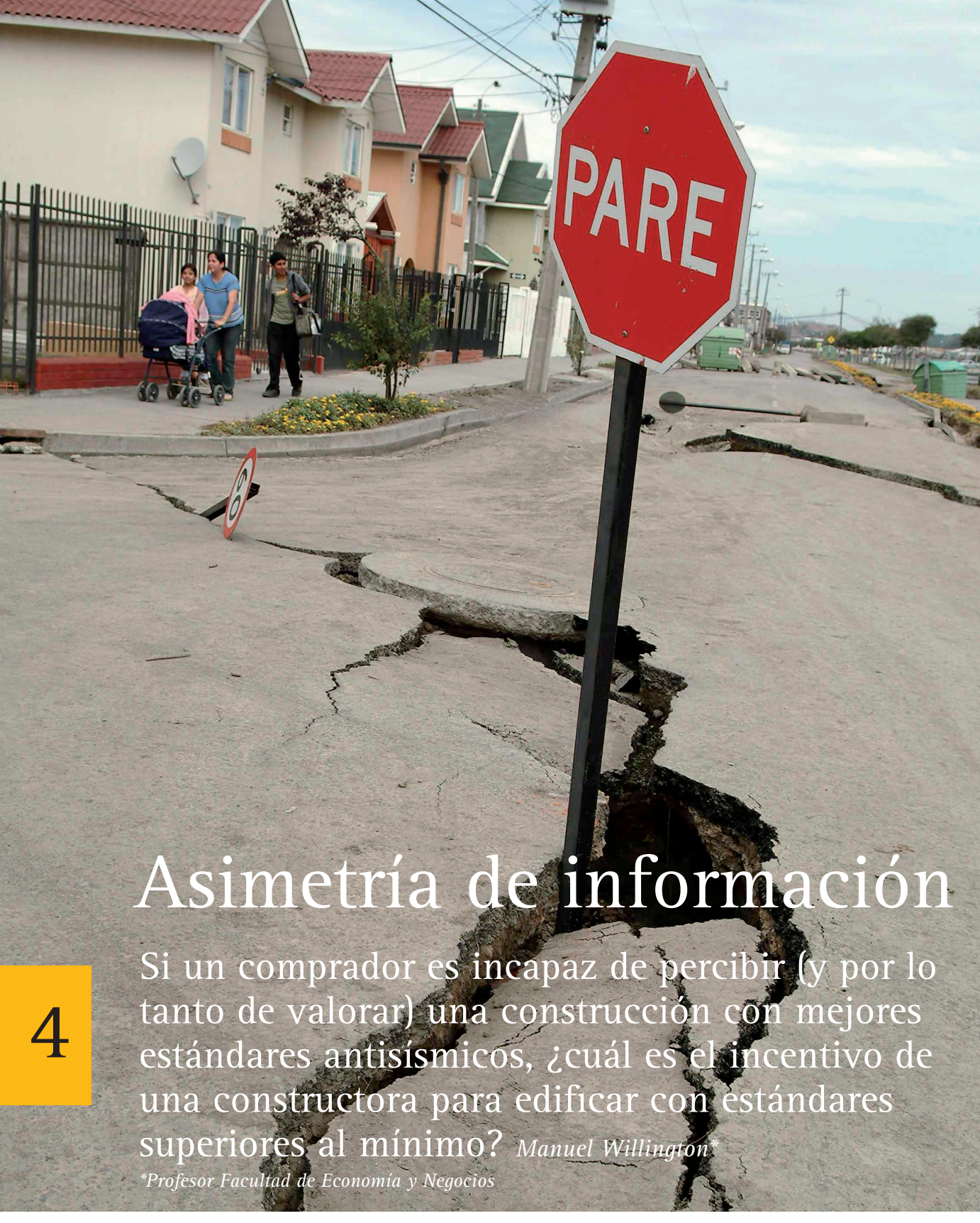

El último terremoto nos mostró, entre lidad. El ejemplo utilizado por Akerlof es otras cosas, que la calidad de las construc- sencillo (y potente): si al mercado de auciones -incluso de las más nuevas- es muy variable. Algunos edificios sobrevivieron y otros colapsaron o deberán demolerse. Sin embargo, desde la perspectiva de un comprador (antes del terremoto) estos edificios eran indistinguibles. La calidad de la construcción, en lo que se refiere a su capacidad antisismica, es para un comprador "promedio" no observable. Esta variable, sin embargo, seguramente era conocida por las embargo, seguram

George Akerlof, ganador del premio Nobel de Economía en 2001, publicó en 1970 su celebérrimo paper acerca de cómo un mercado en el que los vendedores tienen mejor información que los compradores puede "colapsar", en el sentido de desaparecer o solamente transar los bienes de peor cadiendo este fenómeno). antisismicos, icuál es el incentivo de una usados concurren unos vendedores automóviles de mala calidad, un potencia comprador, incapaz de distinguir la varia"calidad", estaría dispuesto en principo a pagar por la "calidad promedio". Si mbargo, si este pago promedio es insufiente para compensar a un vendedor que sue que su auto es de buena calidad, entonces éste no estará dispuesto a vender su de este mercado vendedores con autos de calidad mala (y, lógicamente, el comprador sofisticado ajustará su disposición enten-

En el caso de las viviendas en Chile podría . periores al minimo?

En la jerga de los economistas, estos son mastiontrica en no es óptimo. En algunos casos este tipo de "fas optino. En algunos casos este tipo de intervención del Estado y, en otros, pueden cenerarse mecanismos de mercado que ayudan a paliar la ineficiencia. En el caso de los autos usados, por garantías como forma de señalizar calidad, o puede aparecer un tercero que, por un cobro, evalúa y emite un juicio sobre a calidad del automóvil. En el caso de las viviendas, los sismos generan información valiosa, pero obviamente es un mecanismo ineficiente por ser ex post $y$, afortunadamente, esporádico
La solución (pública o privada) idealmente debe ir al meollo del problema: Jos mecanismos mediante los que el Estado puede ayudar.

En primer lugar, al igual que en otros ámviendas sean inspeccionadas y certificadas (al menos los edificios que son los de mayor riesgo y cuya inspección, por vivienda resultaría más económica). La certificación, idealmente, debería proveer más información que el simple cumplimiento de los estándares minimos que, se supone, es verificado actualmente. En paises desarrollados existen ya experiencias de certificaciones de edificios en cuanto a cumplimiento de estándares medioambientales. En Chile, de manera incipiente, empresas que realizan Inspecciones Técnicas de Obras (ITO) están proveyendo servicios de certificación más sofisticados que el mero cumplimiento de definido en el proyecto que implica la ITO. El segundo mecanismo es obligar a contratar seguros contra sismos, más alla de la existencia o no de una hipoteca sobre la civienda. Por un tema de economias de esde los compradores individules, si podria a frontar el costo de informarse de la calidad de las construcciones $y$, en la medida que mercado de seguros sea relativamente competitivo, esta información se traspasaria los compradores vía primas de seguros. obligatoriedad de comprar seguros contra sismos tendria la ventaja adicional de evitar que el Estado en muchos casos, termine siendo el asegurador "de última instancia" después de un terremoto. La eventual ayuda del Estado a sectores de menores recursos para reconstruir sus vivienda post-terremoto podría canalizarse ex ante, vía subsidio a demanda del seguro.

\section{¿El futuro inmobiliario?}

Pablo Gonzalez M.

Chile fue golpeado por un terremoto de que pasaron bien "la prueba" podrían ob-

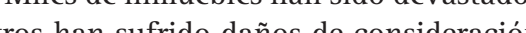
Ea realidad es que la oferta de inmubles e ha reducido en forma importante $\mathrm{N}$ sólo en cantidad, sino en calidad. Habra casas y edificios que ahora serán reparados, pero será difícil quitarles ese sello: "Reparado"

Posiblemente la velocidad de construcción de nuevas viviendas lleve más tiempo que el normal. Luego de las evidentes pión serán lorco pensar que las nuevas onstrucciones requerirán de estándares más elevados, cuyos niveles serán definidos sobre bases científicas y profesional luego de algún tiempo de estudio. En otras palabras, necesitaremos un tiempo para definir que tipo de construcciones requerimos y ademàs, seguramente, los costos y tiempos de construcción serán mayores. Todo lo anterior se refleja en una repacios habitables, aue, como cus y libro de texto de principios de economía explicaría, podría llevar a un aumento de precios (tanto de las viviendas como los arriendos).

remento parejo para todo tipo de vivien
tada sería no. Tal como varios observadores del muncado debiera realizar un recomodo de precios relativos producto del cambio en demanda. No sería descabellado pensar que antes de comprar un departamento veces. El reacomodo a pensarlo al menos dos a favor de las viviendas de baja altura. Incluso aquellos departamentos y edificios seguramente en menor medida.

¿Pro que pasa a nivel macro? Observaviviendas y bienes durables se han visto educidos a la nada o poseerán ahora un menor valor de mercado.

a reconstruccion seguramente requeira del crédito para financiar las nuevas dras. Pero el problema es que en su mayoria esos créditos requieren de una gafor (o colateral) que nomalmente toma qué ofrecer. Los que aún poseen, puede ser que vean disminuido el valor de sus activos y, por lo tanto, requieran de garantías xtras para lograr el crédito. Para peor, lamentablemente, la proyección a mediano y largo plazo más lógica del precio $d$ e as viviendas aun existentes debiera ser baja, en concordancia con el aumento paulatino de la oferta a lo largo del perioLa seconstrucción. pero esto eleva los rieggos de no pago por lo tanto, se reflejaría en una mayor asa de interés o en una exposición mayor riesgo de parte del sistema financiero. Otra alternativa: el subsidio a las tasas o garantia del Estado, pasando al conjunto de todos los contribuyentes la absorción del riesgo derivado. Esta alternativa podia generar hequidad, dado que el beney or le tanter de la magnitud del crédito plativamente más a los sectores con maor capacidad económica.

Lamentablemente este terremoto, que anto daño ha causado al país, puede manifestar sus réplicas muy diversos planos
de la vida de los chilenos.

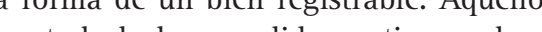

Le podrían bajar 